\title{
IMPLEMENTASI PRESENSI ELEKTRONIK UNTUK MENINGKATKAN KEDISIPLINAN GURU DAN PEGAWAI DI SEKOLAH DASAR ISLAM
}

\author{
Maulidatul Khasanah \\ UIN Maulana Malik Ibrahim Malang \\ maulidatulkhasanah58@gmail.com \\ Walid Fajar Antariksa \\ UIN Maulana Malik Ibrahim Malang \\ walidfjr@mpi.uin-malang.ac.id
}

DOI: 10.35719/jieman.v3i2.82

\begin{abstract}
Abstrak
Beberapa lembaga pendidikan telah menerapkan sistem presensi elektronik model fingerprint untuk meningkatkan kedisiplinan pegawai dan guru. Penerapan presensi elektronik dengan model fingerprint memiliki kelebihan dalam pencatatan dibanding presensi manual. Penelitian ini bertujuan untuk menjelaskan implementasi presensi elektronik di sekolah dan dampaknya dalam meningkatkan kedisiplinan pegawai dan guru. Lokasi dalam penelitian ini adalah di sebuah sekolah dasar Islam di Malang. Penelitian ini menggunakan pendekatan kualitatif dengan jenis penelitian studi kasus. Teknik pengumpulan data yang dipakai adalah wawancara, observasi, dan dokumentasi. Hasil penelitian menunjukkan bahwa penggunaan sistem presensi fingerprint adalah sangat mudah. Pengelola Sekolah juga membuat beberapa aturan agar sistem presensi ini dapat berjalan dengan optimal. Evaluasi tentang kehadiran dilakukan tiap bulan. Guru dan pegawai yang tidak hadir atau tercatat terlambat akan mendapatkan sanksi dari sekolah. Penerapan
\end{abstract}


JIEMAN: Journal of Islamic Educational Management

presensi elektronik di sekolah dasar Islam adalah sudah baik dalam meningkatkan kedisiplinan guru dan pegawai di sekolah.

Kata Kunci: presensi elektronik, kedisiplinan, guru, pegawai

\begin{abstract}
Several educational institutions have implemented fingerprint attendance systems to discipline employees and teachers. The application of fingerprint attendance has advantages in recording compared to manual attendance. This study aims to explain the implementation of electronic attendance in schools, explain the results of the evaluation, and explain how the impact on disciplining employees and teachers. The location of this research is at SD Islam in Malang. This research uses a qualitative approach with a case study approach. Data collection techniques used are interviews, observation, and documentation. The results show that the use of the fingerprint presence system is very easy. School management also makes several rules and evaluation programs so that the attendance system can run optimally. Evaluation of attendance was carried out every month. Teachers and employess who were absent or regestered late would be punished by the school. The application of electronic attendance is that it has been good in disciplining teachers and employees.
\end{abstract}

Keywords: electronic attendance, discipline, teacher, employee

\title{
Pendahuluan
}

Presensi merupakan suatu bukti bahwa seorang pegawai hadir dan bekerja pada sebuah lembaga atau instansi. Pencatatan kehadiran pegawai adalah salah satu faktor penting dalam pengelolaan sumber daya manusia. Informasi tentang kehadiran seorang pegawai dapat menentukan prestasi kerja seseorang, gaji atau upah, produktivitas, dan kemajuan instansi lembaga tersebut. Pencatatan absensi pegawai yang konvensional memerlukan banyak campur tangan pegawai bagian administrasi juga kejujuran pegawai yang sedang dicatat kehadirannya. Hal ini sering memberikan 
peluang manipulasi data kehadiran apabila supervisi tidak dilakukan dengan semestinya. ${ }^{1}$

Perkembangan teknologi pada zaman sekarang berkembang dengan sangat pesat. Dalam hitungan detik, informasi dapat disampaikan secara cepat dengan adanya teknologi informasi. Hal ini menjadikan banyak perusahaan di zaman sekarang yang mengelola usahanya dengan memanfaatkan sistem informasi manajemen. ${ }^{2}$

Sistem informasi merupakan suatu sistem berbasis komputer yang menyediakan informasi bagi beberapa pengguna yang tergabung dalam suatu organisasi. Informasi ini mempunyai pengertian yaitu data yang di olah ke dalam suatu bentuk yang memiliki arti yang nantinya digunakan untuk mengambil keputusan. Sistem informasi ini berisi mengenai data penting seperti data orang, tempat, dan segala apapun yang ada di dalam atau di luar organisasi. Dalam sistem informasi ini memiliki tiga aktivitas dasar di dalamnya seperti, aktivitas masukan (input), pemrosesan (processing), dan keluaran (output). Aktivitas tersebut dapat digunakan oleh organisasi untuk mengambil keputusan. ${ }^{3}$

Setiap organisasi yang menciptakan produk baik berupa barang ataupun jasa, memerlukan sumber daya dalam memproses produknya. Salah satu sumber daya yang utama adalah sumber daya manusia (SDM). Sumber daya manusia merupakan potensi yang terdapat dalam diri manusia untuk mewujudkan perannya sebagai makhluk sosial yang adaptif dan transformasi yang mampu mengelola dirinya menuju tercapainya kesejahteraan kehidupan dalam tatanan yang seimbang dan berkelanjutan. SDM harus dikelola dengan sistem yang baik agar dapat menghasilkan kinerja yang baik. Kinerja pegawai didefinisikan sebagai kemampuan

${ }^{1}$ Lia Sepda Kristin, I. Nyoman Suputra, and Sarbini, "Pengaruh Penerapan Presensi Sidik Jari (Fingerprint) Terhadap Kinerja Guru Melalui Motivasi Kerja Di SMA Negeri 5 Malang," JPBM (Jurnal Pendidikan Bisnis Dan Manajemen) 2, no. 3 (November 1, 2016): 170-77.

2 Raymond Mcleod Jr, Sistem Informasi Manajemen, Ed. VIII, (Jakarta: PT Prenhallindo, 1998), 92.

3 Djoko Sutomo, Sistem Informasi Manajemen, (Pusat Pendidikan dan Pelatihan Pengawasan Badan Pengawasan Keuangan dan Pembangunan, 2007), 7. 
pegawai dalam melakukan sesuatu keahlian tertentu. Kinerja harus memiliki kriteria yang jelas dan terukur agar dapat ditetapkan sebagai acuan bersama. ${ }^{4}$ Kinerja dapat dioptimalkan melalui beberapa hal, seperti penetapan deskripsi jabatan yang jelas dan terukur, seleksi dan orintasi pegawai, pelatihan dan pengembangan, serta penilaian kinerja yang objektif. ${ }^{5}$

SDM dalam institusi pendidikan terdiri dari tenaga pendidik dan tenaga kependidikan. Menurut UU No 20 tahun 2003 tentang Sistem Pendidikan Nasional pasal 1 ayat 6, pendidik adalah tenaga kependidikan yang berkualifikasi sebagai guru, dosen, konselor, pamong belajar, widyaiswara, tutor, instruktur, fasilitator, dan sebutan lain yang sesuai dengan kekhususan nya serta berpartisipasi dalam menyelenggarakan pendidikan. ${ }^{6}$ Sedangkan tenaga kependidikan menurut UU No 20 tahun 2003 tentang Sistem Pendidikan Nasional pasal 1 ayat 5 dijelaskan memiliki tugas administrasi, pengelolaan, pengembangan, pengawasan, dan pelayanan teknis untuk menunjang proses pendidikan pada satuan pendidikan. ${ }^{7}$

Seorang guru atau pegawai dalam menjalankan tugas diharuskan dapat memberikan contoh yang baik, salah satunya yaitu mengenai kedisiplinan ${ }^{8}$. Disiplin merupakan perasaan taat dan patuh terhadap nilai-nilai yang dipercaya termasuk melakukan pekerjaan tertentu yang dirasakan menjadi tanggung jawab. Kedisiplinan merupakan fungsi yang penting dalam manajemen sumber daya manusia karena semakin pegawai disiplin maka semakin tinggi juga prestasi kerja yang dapat dicapai. Disiplin tidak

${ }^{4}$ Lijan Poltak Sinambela, Manajemen Sumber Daya Manusia, (Jakarta: PT Bumi Aksara: 2016), 478.

5 Pianda, Didi,Kinerja Guru: Kompetensi Guru, Motivasi Kerja, Kepemimpinan Kepala Sekolah, (Sukabumi: CV Jejak, 2018), 11.

${ }^{6}$ UU No 20 tahun 2003 tentang Sistem Pendidikan Nasional pasal 1 ayat 6.

${ }^{7}$ UU No 20 tahun 2003 tentang Sistem Pendidikan Nasional pasal 39 ayat 1.

8 Luluk Kusniati, Penggunaan Face Recognition Untuk Meningkatkan Disiplin Kehadiran Pegawai Negara Sipil, (Jurnal Manajemen Pendidikan Volume 25, Nomor 1, Maret 2016), 96. 
harus datang tepat waktu saja, tetapi disiplin dalam segala hal apapun.

Disiplin kerja menurut Mangkunegara ada dua macam, yaitu disiplin preventif dan disiplin korektif. Disiplin preventif merupakan suatu upaya untuk menggerakkan pegawai untuk mengikuti dan mematuhi pedoman dan aturan kerja yang ditetapkan oleh organisasi. Disiplin preventif dilakukan dengan memberikan peringatan atau himbauan agar pegawai tidak melanggar aturan yang telah ditetapkan ${ }^{9}$. Pimpinan organisasi bertanggung jawab untuk membangun iklim organisasi yang mengarah pada penerapan disiplin yang preventif. Di sisi lain, para pegawai juga wajib mengetahui, memahami dan melaksanakan semua pedoman, peraturan hingga Standar Operasi Prosedur (SOP) yang ditetapkan dalam organisasi.

Disiplin korektif adalah upaya menggerakkan pegawai dalam menyatukan suatu peraturan dan mengarahkannya agar tetap mematuhi berbagai peraturan sesuai dengan pedoman yang berlaku pada organisasi dengancara memberikan sanksi kepada pegawai yang melakukan pelanggaran. Sanksi diberikan dengan tujuan agar pegawai tersebut dapat memperbaiki diri dan mematuhi aturan yang ditetapkan.

Salah satu cara untuk mengetahui disiplin waktu yaitu dengan melihat data kehadiran seseorang. Data kehadiran disusun dan diatur sedemikian rupa dengan tujuan apabila diperlukan sewaktuwaktu oleh pihak yang berkepentingan dapat mudah dicari datanya. Secara umum presensi dikelompokkan menjadi 2 yaitu presensi manual dan presensi elektronik. Presensi manual adalah memasukkan data kehadiran dengan cara tanda tangan menggunakan alat tulis pada lembaran kertas presensi. Sedangkan presensi elektronik adalah memasukkan data kehadiran dengan cara menggunakan sistem terkomputerisasi. Salah satu model yang digunakan dalam presensi elektronik adalah model fingerprint. Fingerprint adalah sistem presensi elektronik yang digunakan untuk

${ }^{9}$ A.A. Anwar Prabu Mangkunegara, Manajemen Sumber Daya Manusia Perusahaan, (Bandung : PT. Remaja Rosdakarya, 2016).

Vol. 3, No. 2, Desember 2021 
pengabsenan kehadiran guru dan tenaga kependidikan di sekolah dengan cara scan sidik jari. Pada era globalisasi sekarang ini, presensi manual sudah mulai ditinggalkan oleh berbagi lembaga pendidikan dan digantikan dengan sistem presensi elektronik model fingerprint.

Teknologi yang digunakan pada mesin fingerprint adalah teknologi Biometric. Biometrika atau Biometric berasal dari kata bio dan metric. Bio berarti sesuatu yang hidup dan metric berarti mengukur. Jadi biometrika adalah mengukur karakteristik pembeda pada badan atau perilaku seseorang yang digunakan untuk melakukan pengenalan secara otomatis terhadap identitas orang tersebut dengan cara membandingkannya dengan karakteristik yang sebelumnya telah tersimpan di database. Ada beberapa teknologi biometric yang digunakan yaitu sidik jari, tangan, bentuk wajah, suara, dan retina. ${ }^{1}$

Teknik pembacaan sidik jari pada alat fingerprint disebut dengan optik. Sistem ini akan merekam atau menscan dengan menggunakan cahaya. Alat perekam yang digunakan adalah berupa kamera digital. Tempat untuk meletakkan ujung jari dinamakan permukaan sentuh (scan area). Terdapat lampu atau pemancar cahaya yang menerangi permukaan ujung jari. Hasil pantulan cahaya dari ujung jari tersebut masuk kedalam memori. Scanning sidik jari dilakukan dengan alat elektronik fingerprint. Hasil scanning lalu disimpan dalam format digital pada saat registrasi atau enrollment atau pendaftaran sidik jari. Rekaman sidik jari diproses dan dibuatkan daftar pola fitur sidik jari yang kemudian disimpan dalam memori atau database. Pada saat identifikasi, fitur sidik jari dicocokan dengan hasil scan jari. ${ }^{1}$

Presensi elektronik dianggap memiliki lebih banyak keungulan dibanding presensi manual. Penelitian dari Desmarini dan Kasman meyimpulkan bahwa Presensi elektronik dengan

1 Darma Putra, Sistem Biometrika, (Yogyakarta. Andi Offset, 2008), 21.

1 Heni Jusuf, Ariana Azimah, and Winarsih St, "Pengembangan Aplikasi Sistem Absensi Dosen dengan Menggunakan Fingerprint (Sidik Jari Digital ) di Universitas Nasional," Rekayasa Teknologi 5, no. 1 (April 1, 2013), https://journal.uhamka.ac.id/index.php/rektek/article/view/142. 
menggunakan fingerprint lebih mudah dan efisian saat digunakan. Data yang didapatkan juga lebih akurat karena tidak bisa diwakilkan oleh orang lain sebagaimana presensi manual, sehingga tidak bisa dimanipulasi mengingat tiap orang memiliki sidik jari yang berbedabeda. Penerapan presensi fingerprint dapat lebih meningkatkan kedisiplinan pegawai di lembaga pendidikan. Penelitian dari Kristin menjelaskan bahwa penerapan presensi fingerprint memberikan pengaruh yang signifikan dan bersifat positif terhadap motivasi kerja guru di sekolah. Selain itu, penerapan presensi fingerprint juga berpengaruh terhadap kinerja guru baik secara langsung mapunu tidak langsung. ${ }^{1}$

Sebuah Sekolah Dasar Islam di Malang menerapkan presensi elektronik dengan model fingerprint untuk seluruh guru dan tenaga kependidikannya. Dengan adanya sistem Fingerprint ini pengelola sekolah berharap dapat memantau dengan lebih akurat tentang siapa saja guru atau yang sering hadir dan yang sering tidak hadir. Tujuan diterapkannya presensi ini adalah untuk lebih mendisiplinkan guru dan tenaga kependidikan di sekolah tersebut. Berdasarkan konteks penelitian di atas, peneliti ingin mengetahui tentang penerapan presensi elektronik untuk meningkatkan kedisiplinan guru dan pegawai di Sekolah Dasar Islam.

Penelitian-penelitian sebelumnya telah banyak membahas tentang penerapan presensi elektronik di berbagai lembaga seperti lembaga bisnis ataupun lembaga pemerintah. Akan tetapi masih sedikit penelitian yang membahas penerapan presensi elektronik di sekolah dasar Islam. Dengan adanya penelitian ini diharapkan dapat memberi kontribusi dalam keilmuan bidang manajemen pendidikan Islam khususnya tentang penerapan presensi elektronik dalam meningkatkan kedisiplinan guru dan pegawai.

1 Desmarini Desmarini and Rukun Kasman, "Penerapan Absensi Finger Print Untuk Meningkatkan Disiplin Kerja Pegawai," JMKSP (Jurnal Manajemen, Kepemimpinan, Dan Supervisi Pendidikan) 5, no. 1 (January 30, 2020): 77-83, doi:10.31851/jmksp.v5i1.3540. 
Penelitian ini menggunakan metode kualitatif deskriptif dengan jenis penelitian studi kasus. ${ }^{1}$ Lokasi penelitian adalah di Sekolah Dasar Islam Mohammad Hatta di kota Malang. Data diambil dengan teknik wawancara, observasi dan dokumentasi. Informan dalam penelitian ini adalah Kepala Sekolah, Wakil Kepala Sekolah, Kepala tata Usaha serta guru dan pegawai. Untuk pengecekan keabsahan data, digunakan teknik triangulasi sumber dan triangulasi metode. Data dianalisis dengan metode Miles dan hubberman yang meliputi Reduksi data, penyajian data, verifikasi data dan kesimpulan.

\section{Pembahasan}

\section{Proses Penerapan Presensi Elektronik}

Tujuan penggunaan presensi fingerprint ini adalah supaya data kehadiran guru dan pegawai dapat terekam dengan baik dan tidak dimanipulasi. Tujuan akhir yang diharapkan adalah agar meningkatkan kedisiplinan para guru dan pegawai. Berdasarkan wawancara dengan kepala sekolah, presensi fingerprint di SD Islam Mohammad Hatta Malang dimulai sejak tahun 2012. Presensi fingerprint ini digunakan oleh semua pegawai sekolah, mulai dari kepala sekolah, guru, tenaga administrasi sampai tenaga kebersihan maupun tenaga keamanan. Presensi elektronik ini dikoordinasikan oleh Kepala Tata Usaha. Sebelum adanya presensi fingerprint, pegawai bisa titip presensi kepada temannya. Setelah menggunakan fingerprint, data kehadiran menjadi lebih akurat.

Pada penggunaan mesin presensi fingerprint, operator harus meregistrasi sidik jari pegawai terlebih dahulu. Setelah itu operator mengupload data identitas pegawai serta hasil scan sidik jari dan memastikan bahwa data tersebut sudah benar. Kemudian, operator mengatur jam kerja seperti kedatangan (o6.30 WIB) dan kepulangan (15.30 WIB).

Peneliti mengamati langsung proses presensi. Proses tersebut sangat cepat terekam datanya dan tidak membutuhkan waktu yang

1 Sugiyono, Metode Penelitian Pendidikan?. Kuantitatif, Kualitatif, Kombinasi, RED Dan Penelitian Pendidikan (Bandung: Alfabeta, 2021). 
lama. Guru atau pegawai sangat mudah menggunakan mesin presensi fingerprint, hanya perlu meletakkan jarinya pada mesin presensinya, maka secara otomatis data pegawai tersebut akan tersimpan secara online dalam database kepegawaian.

Berdasarkan aturan yang ditetapkan yayasan yang menaungi sekolah, guru atau pegawai datang terlambat diharuskan mengisi formulir keterlambatan untuk diserahkan ke pimpinan sekolah dan dipotong uang transportasi sesuai dengan berapa kali keterlambatan. Akan tetapi dalam pelaksanaannya hal tersebut tidak dilakukan. Kepala sekolah akan melihat hasil rekapan presensi selama satu bulan dan kemudian memanggil guru atau pegawai yang terlambat lebih dari 5 kali dalam sebulan dan kemudian akan memberi sanksi. Pihak Sekolah juga memberi dispensasi 5 menit pada jam datang. Artinya jika ada guru atau pegwai yang datang jam o6.35 wib maka masih dimaafkan, dan apabila datangnya lebih dari jam o6.35 maka akan dicatat terlambat dan akan mendapatkan sanksi.

Penerapan presensi elektronik ini sesuai dengan penjelasan Ben Arian bahwa tujuan dari sebuah teknologi adalah memberikan kemudahan dan solusi yang lebih baik dan sesuai dengan tantangan perkembangan zaman. ${ }^{1}$ Penerapan yang dilakukan di SD Islam juga sesuai dengan konsep tahap penggunaan absensi sidik jari yaitu (1) Registrasi sidik jari pegawai, (2) Download data dan sidik jari pegawai, (3) Upload data pegawai, (4) Mengatur jam kerja, (5) Download data presensi, dan (6) Kalkulasi laporan. Agar penerapan presensi elektronik dapat berjalan dengan baik, maka harus ada aturan penegakan disiplin pegawai. ${ }^{1}$

SD Islam Mohammad Hatta Malang memberlakukan sanksi bagi yang terlambat kedatangan masuk. Batas maksimal kedatangan yaitu pukul 06.35 WIB. Apabila waktu kedatangan lebih dari jam yang ditentukan maka akan dikatakan terlambat apabila tidak ada

1 Ben Adrian, Amazing Fingerprint Teknologit Penelusuran Watak dan Bakat, (Bandung: Talent Spectrum, 2018), 1.

1 Muhammad Gazali Sina, “Efektivitas Pemásangan Absen Sidik Jari (Finger Scan) Dalam Meningkatkan Disiplin Kerja Pegawai Rektorat Universitas Mulawarman Samarinda”, eJournal Ilmu Pemerintahan, 2016), 219. 
keterangan alasan yang syar'i seperti fotokopi soal ujian, penyebaran brosur sekolah, dll. Sanksi bagi yang terlambat yaitu pemotongan gaji. Meskipun pemotongan gaji tidak besar tetapi itu untuk menentukan kedisiplinan seseorang. Tujuan diberlakukannya pemotongan gaji bagi yang terlambat yaitu untuk mendisiplinkan guru dan pegawai, selain itu juga untuk membedakan antara yang sering terlambat dan itu merupakan rapot bagi karyawan bahwa dia kurang disiplin.

Penerapan sanksi di SD Islam Mohammad Hatta Malang sesuai dengan teori Manajemen Sumber Daya Manusia yang dijelaskan oleh Hasibuan. Pemberian sanksi bertujuan untuk menjaga kedisiplinan pegawai. Berat atau ringannya sanksi hukuman yang akan diterapkan akan ikut mempengaruhi baik/buruknya kedisiplinan pegawai. Sanksi hukuman harus diterapkan berdasarkan pertimbangan yang logis, masuk akal, dan di informasikan secara jelas kepada semua karyawan. ${ }^{1}$

\section{Evaluasi Penerapan Presensi Elektronik untuk Meningkatkan Kedisiplinan Guru dan Pegawai di Sekolah Dasar Islam}

Evaluasi kinerja guru dan pegawai di SD Islam Mohammad Hata Malang dilakukan setiap bulan sekali oleh kepala Sekolah. Salah satu indikator yang dievaluasi dalam evaluasi bulanan adalah tentang presensi guru dan pegawai. Tujuan diadakannya evaluasi yaitu untuk memberitahukan siapa saja yang datang terlambat dan berapa orang yang terlambat. Setelah diketahui siapa saja yang sering terlambat, mereka akan dipanggil oleh kepala sekolah dan diberi sanksi. Adapun sanksinya adalah pemotongan uang transportasi sebesar Rp $\mathbf{1 4 . 0 0 0}$ per hari dikalikan dengan jumlah hari keterlambatan. Tujuan dipanggil kepala sekolah yaitu untuk mengetahui apa alasannya bisa terlambat. Dari permasalahan tersebut akan akan diketahui solusi yang terbaik. Kepala sekolah juga berusaha membantu untuk menyelesaikan permasalahan agar guru atau pegawai di sekolah tidak datang terlambat lagi. Kepala Sekolah

1 Malayu S.P. Hasibuan, Manajemen Sumber Daya Manusia, Ed. Revisi, (Jakarta: PT Bumi Aksara, 2012), 195. 
menegakkan kedisiplinan yang tinggi dan memberikan contoh yang baik bagi yang dipimpinnya. Dengan contoh perilaku tersebut para pegawai dan guru menjadi termotivasi disiplin dalam bekerja di sekolah.

Proses Evaluasi kinerja yang dilaksanakan di SD Islam Mohammad Hata Malang sesuai dengan berbagai teori tentang evaluasi dalam manajemen. Menurut Rismawati dan Mattalata, Evaluasi kinerja merupakan metode menilai dan menghargai kinerja seorang pegawai atau suatu unit kerja dalam sebuah organisasi sesuai dengan standar yang telah ditetapkan. Evaluasi kinerja melibatkan komunikasi dua arah yaitu antara pengirim pesan dengan penerima pesan sehingga komunikasi dapat berjalan dengan baik. Evaluasi kinerja dilakukan untuk memberi tahu karyawan apa yang diharapkan pengawas untuk membangun pemahaman yang lebih baik satu sama lain. Evaluasi kinerja menitikberatkan pada evaluasi sebagai suatu proses pengukuran sejauh mana kerja dari orang atau sekelompok orang dapat bermanfaat untuk mencapai tujuan yang ada. ${ }^{1}$

Pemberian sanksi dengan memotong kompensasi pegawai bertujuan agar pegawai tersebut dapat bertindak disiplin. Hal ini sesuai dengan teori bahwa tujuan utama setiap organisasi dalam merancang sistem kompensasi adalah untuk memotivasi karyawan dalam meningkatkan kinerjanya serta mempertahankan karyawan yang berkompeten. Salah satu tujuan seseorang bekerja adalah mengharapkan kompensasi dari organisasi dimana ia bekerja, sedangkan pihak perusahaan mengharapkan karyawan memberikan kinerja yang terbaik bagi organisasi. ${ }^{1}$

Kepala Sekolah di SD Islam Mohammad Hata Malang memiliki peranan yang penting dalam peningatan disiplin guru dan pegawai, yaitu dengan mengingatkan, memberi contoh, dan melakukan evaluasi. Hal ini sesuai dengan penelitian dari Adriyani,

1 Rismawati dan Mattalata, Evaluasi Kinerja: Penilaian Kinerja Atas Dasar Prestasi Kerja Berorientasi Kedepan, (Celebes Media Perkasa, 2018), 5.

1 A. Sihotang, Manajemen Sumber Daya Manưsia, (Jakarta: PT. Pradnya Paramita, 2007), Hlm. 219.

Vol. 3, No. 2, Desember 2021 
Cicilia dan Tutik yang menjelaskan bahwa faktor kepemimpinan berpengaruh terhadap kedisiplinan pegawai. Jika pemimpin bertindak tegas dan disiplin, maka kedisiplinan pegawai juga akan baik. Peran Kepala Sekolah dalam menumbuhkan kedisiplinan antara lain dengan memberikan motivasi, memberikan keteladanan, memperhatikan kesejahteraan dan melaksanakan penegakan kedisiplinan. ${ }^{1}$

\section{Dampak Penerapan Presensi Elektronik untuk Meningkatkan Kedisiplinan Guru dan Pegawai di Sekolah Dasar Islam}

Presensi fingerprint diterapkan di Sekolah dengan tujuan untuk meningkatkan kedisiplinan pegawai. Presensi manual yang telah diterapkan sebelumnya dinilai tidak efektif karena dapat pencatatannya dapat dimanipulasi dan kurang terekam dengan baik. Bersamaan dengan penerapan presensi fingerprint, pihak sekolah juga membuat aturan bahwa ada konsekuensi pemotongan gaji yang harus diterima apabila pegawai datang terlambat. Selain itu akan ada evaluasi rutin setiap bulan. Pegawai yang terlambat akan dipanggil namanya oleh Kepala Sekolah. Hal ni juga akan menimbulkan rasa malu bagi pegawai. Dampak diterapkannya presensi elektronik dan aturan penunjangnya dapat membuat tingkat keterlambatan guru dan pegawai semakin menurun. Hasil rekap kehadiran pegawai di sekolah menunjukkan bahwa pegawai yang datang terlambat jumlahnya sangat sedikit.

Hasil penelitian ini sesuai dengan penelitian dari Desmarini dan kasman yang menyatakan bahwa Presensi fingerprint adalah mudah digunakan dan menghindari perbuatan curang dalam pencatatan kehadiran, sehingga membuat disiplin pegawai menjadi meningkat. ${ }^{2}$ Hasil yang sama juga didapatkan dari penelitian yang

1 Andriyani Andriyani, Cicilia Dyah Sulistyaningrum Indrawati, and Tutik Susilowati, "Peran Kepemimpinan Kepala Sekolah dalam Menumbuhkan Kedisiplinan Guru dan Karyawan,” Jurnal Pendidikan Administrasi Perkantoran 2, no. 1 (June 26, 2014), https://jurnal.fkip.uns.ac.id/index.php/pap/article/view/1532.

2 Desmarini and Kasman, "Penerapan Absensi Finger Print Untuk Meningkatkan Disiplin Kerja Pegawai.” 
dilakukan di SD Negeri 25 Manado, yang menyimpulkan bahwa presensi fingerprint dinilai mampu meningkatkan kedisiplinan kehadiran pegawai di sekolah. ${ }^{2}$ Penelitian lain di Kabupaten kediri juga menyatakan bahwa penerapan presensi elektronik berpengaruh signifikan terhadap kinerja pegawai. ${ }^{2}$ Hasil ini juga mendukung kesimpulan penelitian dari Nurfadilah dan Farihah yang menyatakan bahwa motivasi kerja guru dan disiplin kerja guru berpengaruh terhadap kinerja guru di madrasah. ${ }^{2}$

\section{Simpulan}

Penelitian ini menunjukkan bahwa penerapan presensi elektronik dengan menggunakan fingerprint adalah mudah digunakan serta lebih aman dalam pencatatannya karena sulit untuk dimanipulasi. Evaluasi penerapan presensi elektronik dilakukan setiap bulan sekali oleh Kepala Sekolah. Apabila ada guru atau pegawai yang tidak hadir atau terlambat tanpa alasan yang bisa diterima, maka akan mendapatkan sanksi sesuai dengan yang telah ditetapkan. Penerapan presensi elektronik semakin efektif apabila didukung dengan kepemimpinan yang baik dari kepala sekolah dan dengan penegakan sanksi disiplin bagi yang melanggar. Dampak dari penerapan presensi elektronik adalah dapat meningkatkan kedisiplinan guru dan pegawai, meskipun masih ditemui beberapa pelanggaran yang ditemui diantaranya pegawai yang datang terlambat ke sekolah karena berbagai kondisi dan alasan.

2 Anggelika Nurianto, Welson Y Rompas, land Burhanuddin Kiyai, "Penerapan Disiplin Kerja Pegawai Melalui Absensi Finger Print Di SDN 25 Manado" 6, no. 92 (2020): 10.

2 Nizar Zakaria, "Pengaruh Efektivitas Pen̉erapan Sistem Presensi Electronic Data Capture (Edc) Dan Budaya Organisasi Terhadap Disiplin Kerja Karyawan Pt Bank Rakyat Indonesia (Persero) Tbk Kantor Cabang Pare," REVITALISASI: Jurnal Ilmu Manajemen 5, no. 3 (2019): 81-86.

2 Ita Nurfadilah and Umi Farihah, "Pengaruh Motivasi Kerja Dan Disiplin Kerja Terhadap Kinerja Guru Madrasah,” JIEMAN: Journal of Islamic Educational Management 3, no. 1 (June 30, 2021): 105-28, doi:10.35719/jieman.v3i1.70.

Vol. 3, No. 2, Desember 2021 


\section{Referensi}

Adrian, Ben. Amazing Fingerprint Teknologi Penelusuran Watak dan Bakat. Bandung: Talent Spectrum, 2018.

Andriyani, Andriyani, Cicilia Dyah Sulistyaningrum Indrawati, and Tutik Susilowati. "Peran Kepemimpinan Kepala Sekolah Dalam Menumbuhkan Kedisiplinan Guru Dan Karyawan." Jurnal Pendidikan Administrasi Perkantoran 2, no. 1 (June 26, 2014).

https://jurnal.fkip.uns.ac.id/index.php/pap/article/view/1532

Darma Putra, Sistem Biometrika, Yogyakarta: Andi Offset, 2008

Desmarini, Desmarini, and Rukun Kasman. "Penerapan Absensi Finger Print Untuk Meningkatkan Disiplin Kerja Pegawai." JMKSP (Jurnal Manajemen, Kepemimpinan, Dan Supervisi Pendidikan) 5, no. 1 (January 30, 2020): 77-83. doi:10.31851/jmksp.v5i1.3540.

Hasibun, Malayu S.P. Manajemen Sumber Daya Manusia, Ed. Revisi. Jakarta: PT Bumi Aksara, 2012

Jr, Raymond Mcleod. Sistem Informasi Manajemen, Ed. VIII. Jakarta: PT Prenhallindo, 1998.

Jusuf, Heni, Ariana Azimah, and Winarsih St. "Pengembangan Aplikasi Sistem Absensi Dosen dengan Menggunakan Fingerprint (Sidik Jari Digital ) di Universitas Nasional." Rekayasa Teknologi 5, no. 1 (April 1, 2013). https://journal.uhamka.ac.id/index.php/rektek/article/view/ 142.

Kristin, Lia Sepda, I. Nyoman Suputra, and Sarbini. "Pengaruh Penerapan Presensi Sidik Jari (Fingerprint) Terhadap Kinerja Guru Melalui Motivasi Kerja Di SMA Negeri 5 Malang." JPBM (Jurnal Pendidikan Bisnis Dan Manajemen) 2, no. 3 (November 1, 2016): 170-77. 
Kusniati, Luluk. "Penggunaan Face Recognition Untuk Meningkatkan Disiplin Kehadiran Pegawai Negara Sipil.” Jurnal Manajemen Pendidikan, Volume 25, Nomor 1 (2016).

Nurfadilah, Ita, and Umi Farihah. "Pengaruh Motivasi Kerja Dan Disiplin Kerja Terhadap Kinerja Guru Madrasah.” JIEMAN: Journal of Islamic Educational Management 3, no. 1 (June 30, 2021): 105-28. doi:10.35719/jieman.v3i1.70.

Nurianto, Anggelika, Welson Y Rompas, and Burhanuddin Kiyai. "Penerapan Disiplin Kerja Pegawai Melalui Absensi Finger Print Di SDN 25 Manado" 6, no. 92 (2020): 10.

Pianda, Didi. Kinerja Guru: Kompetensi Guru, Motivasi Kerja, Kepemimpinan Kepala Sekolah, Sukabumi: CV Jejak, 2018.

Rismawati dan Mattalata. Evaluasi Kinerja: Penilaian Kinerja Atas Dasar Prestasi Kerja Berorientasi Kedepan, Makassar: Celebes Media Perkasa, 2018.

Sihotang, A. 2007. Manajemen Sumber Daya Manusia. Jakarta: PT. Pradnya Paramita.

Sina, Muhammad Gazali. "Efektivitas Pemasangan Absen Sidik Jari (Finger Scan) Dalam Meningkatkan Disiplin Kerja Pegawai Rektorat Universitas Mulawarman Samarinda." eJournal Ilmu Pemerintahan, vol 4, No 1 (2016).

Sinambela, Lijan Poltak. Manajemen Sumber daya Manusia. Jakarta: Pt Bumi Aksara, 2016.

Sugiyono. Metode Penelitian Pendidikan: Kuantitatif, Kualitatif, Kombinasi, RED Dan Penelitian Pendidikan. Bandung: Alfabeta, 2021.

Sutomo, Djoko. Sistem Informasi Manajemen. Pusat Pendidikan dan Pelatihan Pengawasan Badan Pengawasan Keuangan dan Pembangunan, 2007.

UU No 20 tahun 2003 tentang Sistem Pendidikan Nasional. 
JIEMAN: Journal of Islamic Educational Management

Zakaria, Nizar. "Pengaruh Efektivitas Penerapan Sistem Presensi Electronic Data Capture (Edc) Dan Budaya Organisasi Terhadap Disiplin Kerja Karyawan Pt Bank Rakyat Indonesia (Persero) Tbk Kantor Cabang Pare.” REVITALISASI: Jurnal Ilmu Manajemen 5, no. 3 (2019): 81-86. 